\title{
Mass budget of the magma flow in the 2000 volcano-seismic activity at Izu-islands, Japan
}

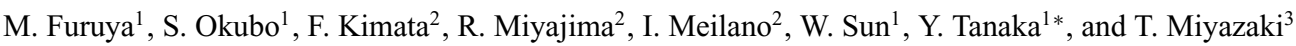 \\ ${ }^{1}$ Earthquake Research Institute, University of Tokyo, Tokyo 113-0032, Japan \\ ${ }^{2}$ Research Center for Seismology and Volcanology, Nagoya University, Nagoya 464-8602, Japan \\ ${ }^{3}$ Bureau of General Affairs, Tokyo Metropolitan Government, Tokyo 163-8001, Japan
}

(Received February 18, 2003; Revised July 17, 2003; Accepted August 15, 2003)

\begin{abstract}
Eruptive and caldera-forming activity at Miyakejima volcano island, Japan, commenced on 26 June 2000 was accompanied by more than 40 day of seismic swarms and significant crustal deformation in the nearby islands and sea region besides those at Miyakejima itself. The migration of the hypocenters in the early stage suggests that they were triggered by magma intrusion from Miyakejima. However, it remains uncertain whether the long-lasting seismic swarms and ground displacements in the northern Izu-islands were totally maintained by the magma flow from Miyakejima, because another magma source nearby Kozushima was suggested previously, which is $40 \mathrm{~km}$ north-west of Miyakejima, based upon anomalous ground displacements. Here we report the detection of associated changes with the 2000 activity in both absolute gravity and elevation at Kozushima as well as those at Miyakejima. Combining these data with horizontal GPS displacements, we extend the analysis of Nishimura et al. (2001) and construct an optimum source model, so that we can account for the observed changes in geodetic data and determine the mass budget of the magma flow. The total mass of the newly intruded dike offshore of Miyakejima and nearby Kozushima turned out to be $130 \%$ or greater than the lost mass at Miyakejima. As long as there are no other source elements, another magma reservoir near Kozushima is required and is suggested to have been activated, causing the seismic swarms and crustal deformation. We may speculate as a phenomenology that the rapid lateral magma flow from Miyakejima in the very beginning of the unrest awakened a dormant reservoir offshore of Miyakejima and Kozushima.
\end{abstract}

Key words: Absolute gravity, leveling, Miyakejima, Kozushima, volcano.

\section{Introduction}

Kozushima is one of the volcano islands in the Izu-Bonin arc at the eastern edge of the Philippine Sea Plate which is subducted by the Pacific Plate (Fig. 1). Historical records tell that the latest eruption goes back to 833 A.D., and it has been dormant for about 1200 years. However, moderate size seismic swarms intermittently occurred in 19651966, 1967, 1988, and 1991-1995 (Japan Meteorological Agency, 1996). Global positioning system (GPS) measurements showed a significant difference in the velocity vector of Kozushima from that predicted by the Philippine Sea Plate motion, and are interpreted in terms of an inflation source beneath Kozushima (Kimata et al., 1994, 2000). Thus, our original motivation of both the leveling measurements made on January 2000 and the microgravity measurements made on March 2000 was to detect spatio-temporal changes in elevation and gravity which might be associated with possible volcanic unrest at Kozushima.

In the meantime, beginning with earthquake swarms on 26 June 2000, eruptive activity started at Miyakejima volcano, which is $40 \mathrm{~km}$ south-east away from Kozushima (Fig. 1). In

*Now at Geographical Survey Institute, Tsukuba, Japan.

Copy right(C) The Society of Geomagnetism and Earth, Planetary and Space Sciences (SGEPSS); The Seismological Society of Japan; The Volcanological Society of Japan; The Geodetic Society of Japan; The Japanese Society for Planetary Sciences. contrast to the Kozushima volcano, the Miyakejima volcano has been rather active, and the average recurrence period of its eruption was estimated to be about 22 years over the past centuries (Miyazaki, 1984). However, the 2000 unrest was accompanied by a caldera collapse, which began on 8 July 2000; geological study suggests that the previous caldera formation goes back 2500 years (Tsukui and Suzuki, 1998). What should be kept in mind for the 2000 Miyakejima caldera formation is that, though the final volume of the collapsed caldera amounts to $0.6 \mathrm{~km}^{3}$ (Hasegawa et al., 2001), the eruption deposits outside the caldera are estimated to be at most $0.011 \mathrm{~km}^{3}$ (Nakada et al., 2001). In view of the hypocenter migration stated below and the modeling results of the gravity changes (Furuya et al., 2003), the disappeared volume of material would be accommodated to the lateral magma flow from Miyakejima toward Kozushima. The GPS Earth Observation NETwork (GEONET) of the Geographical Survey Institute (GSI), Japan, detected a significant crustal deformation not only at Miyakejima but also at nearby islands as well as at Boso peninsula (Fig. 1) (Kaidzu et al., 2000; Nishimura et al., 2001). They were presumably triggered by the magma intrusion from Miyakejima. However, it is debatable whether the long-lasting seismic swarms and anomalous ground displacements in northern Izu-islands were maintained only by the magma flow from Miyakejima (Yamaoka, 2000). On account of the intermittent seismic swarms and unexpected GPS velocity vector at 


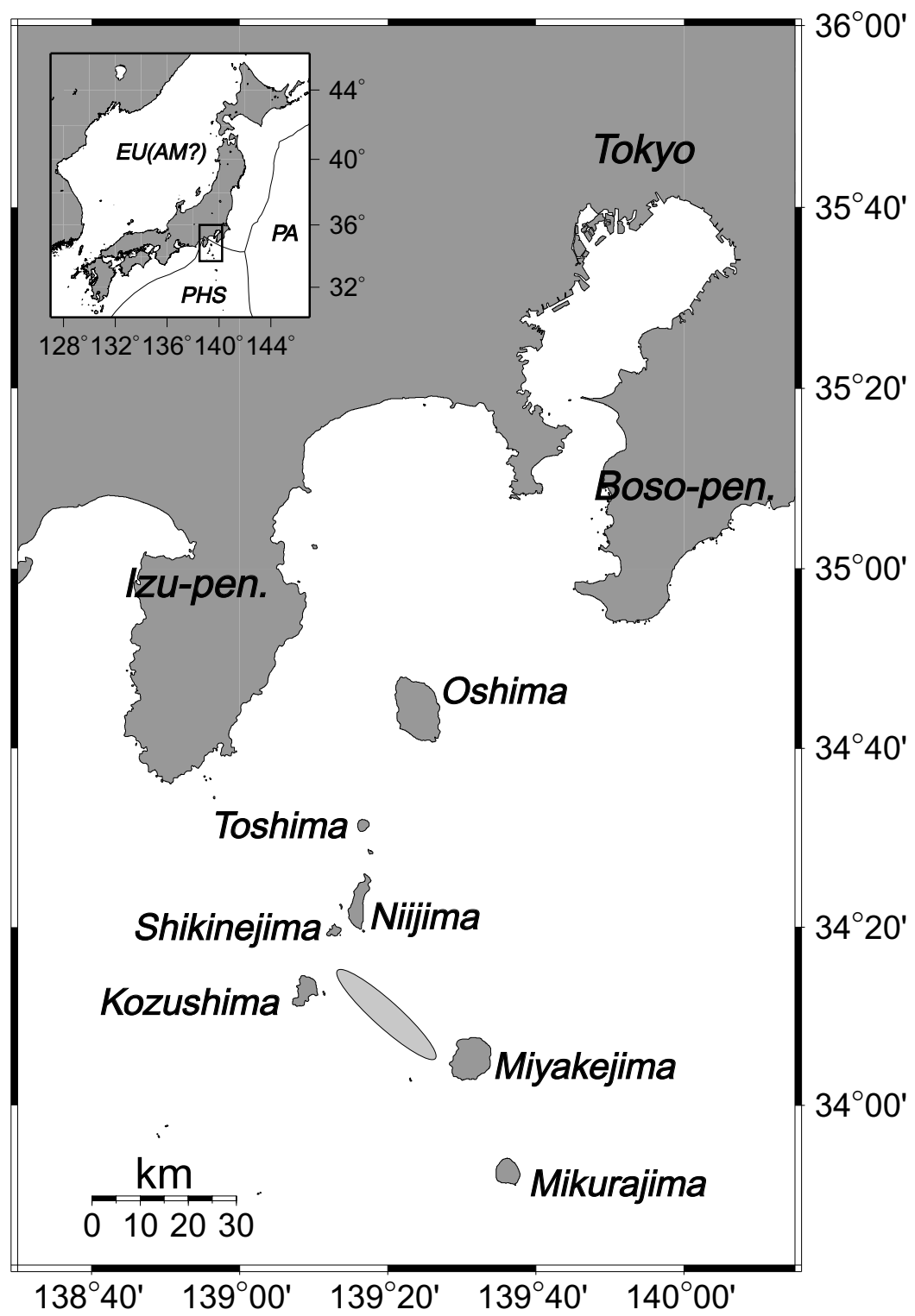

Fig. 1. Location map of Izu-islands, Japan. Shaded region between Kozushima and Miyakejima roughly illustrates where the intense seismic swarms were observed in 2000 (JMA, 2000; Sakai et al., 2001). Inset figure shows Japanese islands, the plate boundary near Japan, and the location of studied area, where EU, PA, and PHS stands for Eurasian, Pacific and Philippine Sea plates, respectively. It is debatable, however, that the western part of Japan belongs to the Amurian (AM) plate.

Kozushima known from before, it is conceivable that other magma nearby Kozushima besides that at Miyakejima was involved during the period of the 2000 event.

The purpose of this paper is to report gravity and elevation changes not only at Miyakejima but also at Kozushima and to develop a source model that may jointly account for the detected changes in gravity and elevation as well as ground displacements derived by GPS (Nishimura et al., 2001). The 2000 volcano-seismic activity at Izu-islands, Japan has provided a unique opportunity for volcano geodesy, using stateof-the-art techniques (Dvorak and Dzurisin, 1997). Combining the gravity change and ground displacement data at other Izu-islands with those at Miyakejima, we can examine a mass budget of the source model. Accordingly, we may answer whether another magma reservoir nearby Kozushima affected the long-lasting swarms and crustal deformation during the 2000 activity at the Miyake-Kozu islands, Japan.
The organization of this paper is as follows. In the next section, the 2000 Izu-Islands volcano-seismic activity is briefly overviewed, referring to our previous paper (Furuya et al., 2003). The following two sections describe results of gravity and elevation changes at Kozushima and those at Miyakejima, respectively. The next section deals with the modeling and the results of parameter optimization. Finally, we summarize our geodetic observation results, and discuss their implications for magma movement during the 2000 Miyake-Kozu islands volcano-seismic activity.

\section{The Izu-Islands Volcano-Seismic Activity in 2000}

Sakai et al. (2001) showed that earthquake hypocenters migrated from Miyakejima toward Kozushima from 26 June to 2 July 2000 by as much as $30 \mathrm{~km}$. The hypocenter migration at that moment presumably represents a dike 

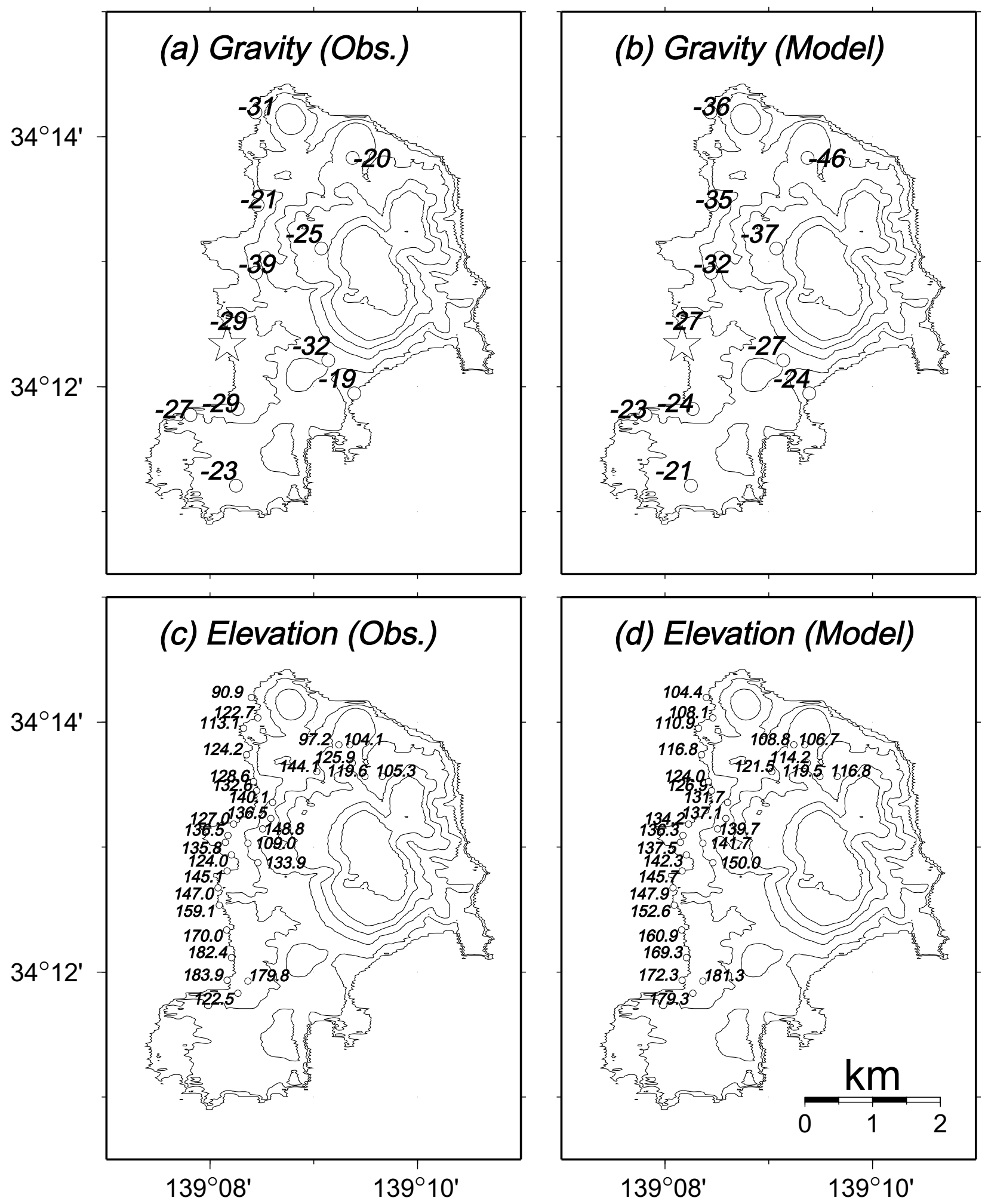

Fig. 2. (a) Observed and (b) computed gravity changes at Kozushima. Units are in microgal. Observed gravity changes were derived by comparing the surveys on March and September 2000. Computed gravity changes are based upon the optimum source model shown in Table 1. Star and dots stand for the absolute and relative gravity sites, respectively. Gravity measurement errors are less than 5 and 20 microgals for absolute and relative gravimetry, respectively. (c) Observed and (b) computed elevation changes at Kozushima. Units are in millimeters. Observed elevation changes were derived by comparing the surveys on January 2000 and April 2001. Topographic contours are shown at intervals of $100 \mathrm{~m}$. Errors in elevation change data are less than $10 \mathrm{~mm}$

intrusion. The hypocenters were distributed along an axis perpendicular to the orientation of maximum tension stress around the region (Nakamura et al., 1984). Though an obvious hypocenter migration from Miyakejima toward
Kozushima was not detected after 2 July, intense seismic swarms in the north-western offshore of Miyakejima lasted more than 40 days (JMA, 2000; Sakai et al., 2001); there also occurred 5 large earthquakes whose magnitude was 


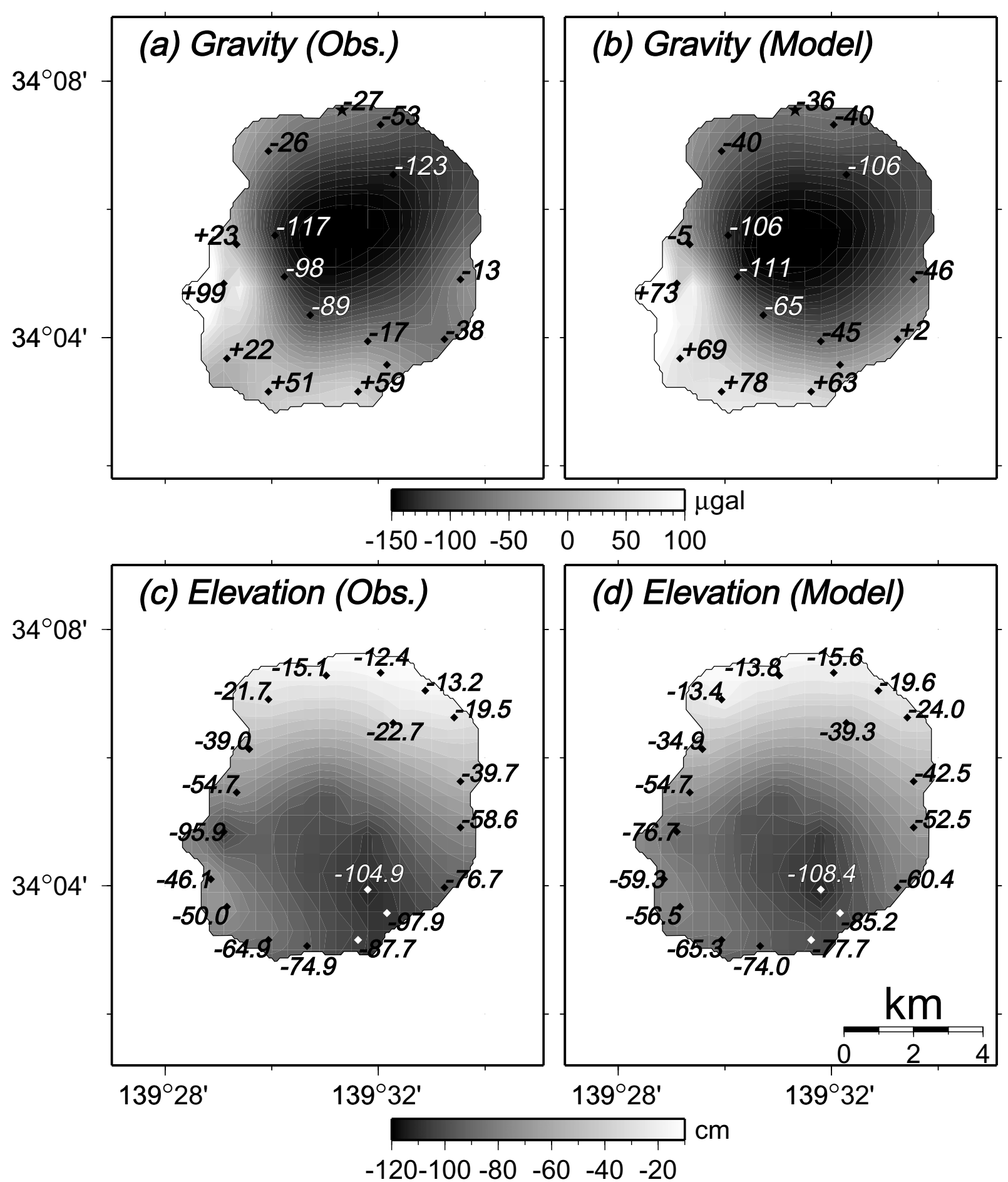

Fig. 3. (a) Observed and (b) computed effective gravity changes at Miyakejima. "Effective" means that the effect of topography change due to the caldera collapse is corrected for. Observed gravity changes were derived by comparing the surveys on June and August 2000. Computed gravity changes are based upon the optimum source model shown in Table 1. Star and dots stand for the absolute and relative gravity sites, respectively. Gravity measurement errors are less than 5 and 20 microgals for absolute and relative gravimetry, respectively. (c) Observed and (b) computed elevation changes at Miyakejima. Observed elevation changes were derived by comparing the surveys on June 1999 and January 2002. Errors in elevation change data are less than $10 \mathrm{~mm}$.

greater than 6. Significant crustal deformation was detected immediately after 26 June not only at Miyakejima but also at Kozushima and other nearby islands (Kaidzu et al., 2000; Nishimura et al., 2001); see also Fig. 4 below. It should also be noted that the anomalous ground movement dramatically slowed down after the largest eruption at Miyakejima on 18 August 2000; for instance, see the baseline between Shikinejima and Kozushima of GSI's GPS (http://www.gsi.go.jp/WNEW/LATEST/ MIYAKE/gps / 0627/mgps-bh30.gif).

The seismicity beneath Miyakejima inactivated after the hypocenter migrated toward Kozushima, but the number of earthquakes showed a dramatic increase around 4 July 2000 (JMA, 2000; Sakai et al., 2001). Accompanying a small 


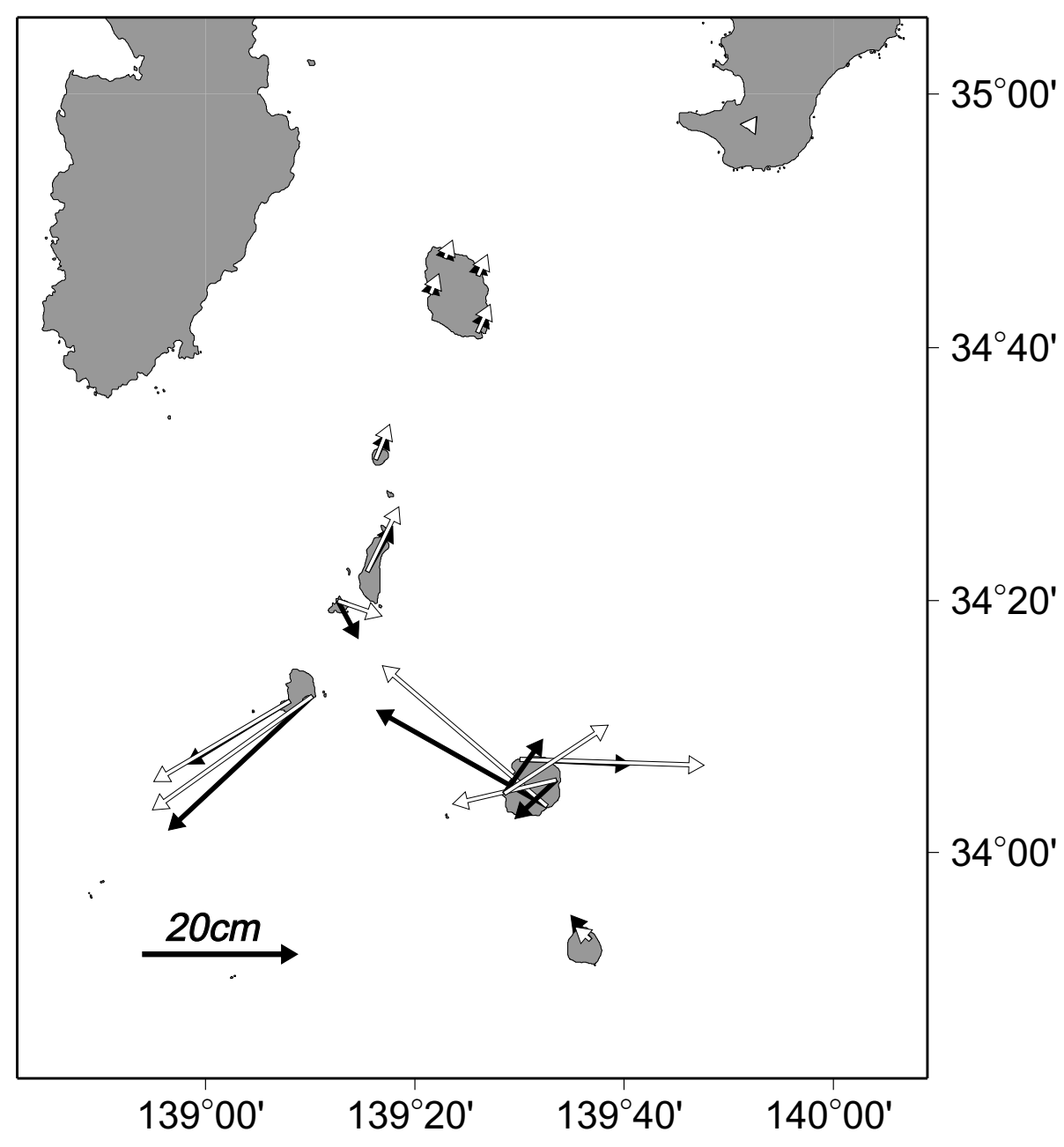

Fig. 4. Observed (black) and computed (white) horizontal ground displacement derived by GEONET GPS. They are derived by comparing the averages on 20-24 June hand those on 1-5 September 2000. There occurred five large earthquakes during this time span, which caused appreciable displacements. Following Nishimura et al. (2001), to see the aseismic deformation alone, we eliminated those co-seismic jumps simply by subtracting the difference on the dates before and after the earthquake.

summit eruption, caldera collapse initiated presumably on the evening of 8 July 2000, which was eye-witnessed on the morning of 9 July 2000. After 11 July, there occurred explosive phreatic and phreato-magmatic eruptions; the largest eruption occurred on 18 August, and its plume top reached as high as $14 \mathrm{~km}$ according to the estimate by JMA (http://www.jma.go.jp/JMA_HP/jma/ press/0008/24a/mate01.pdf). Nevertheless, the total volume of eruption deposits was much smaller than the final volume of the caldera (Nakada et al., 2001). After September 2000, while no large explosive eruptions have been observed at Miyakejima, volcanic gas, in particular sulfur dioxide, started to discharge in unprecedented amounts as much as over $10^{4}$ tons/day. The gas discharge rate reached its maximum from December 2000 to January 2001, when a volcanic glow was also observed during the nights.

Furuya et al. (2003) discussed the temporal evolution of the magma reservoir beneath Miyakejima after the onset of the 2000 unrest. As shown in Fig. 3(a), gravity changes from the beginning of the unrest to the middle of August showed an effective decrease despite the ground subsidence, which were interpreted by a density decrease beneath Miyakejima.
In contrast, gravity values increased after the middle August 2000 at Miyakejima, and they could not be explained by the ongoing ground subsidence alone. Furuya et al. (2003) suggested that shallower magma chamber started to be refilled.

The turning point of the temporal gravity changes occurred in the middle August 2000, which has an important implication. We consider that, owing to the largest eruption as of 18 August, there formed an open conduit from the surface to the magma reservoir at Miyakejima, and that a substantial part of the caldera collapse and lateral magma flow came to an end by 18 August 2000. According to the continuous crustal deformation monitoring by GEONET, more than $90 \%$ of the detected changes were presumably caused by the most intensive activity from 26 June to the middle of August 2000. Thus, we think that the observed changes in geodetic observables at Izu-islands are interrelated until the middle August 2000, and that volcanic activity at Miyakejima after September 2000 does not affect other Izu-islands. Accordingly, although the campaign measurement periods for elevation and gravity differ from each other, the source model may constrain the mass budget of magma flow during the 2000 activity at Izu-islands, Japan. 
Table 1. Source parameters for model shown in Fig. $5^{a}$.

\begin{tabular}{|c|c|}
\hline Deflation source & Values \\
\hline Location (deg. long. E, deg. lat. N) & $139.52,34.08$ \\
\hline Deflated volume $\left(\mathrm{m}^{3}\right)$ & $-1.32 \pm 0.05 \times 10^{8}$ \\
\hline Depth $(\mathrm{km})$ & $4.6 \pm 0.2$ \\
\hline \multicolumn{2}{|l|}{ Lightened body $y^{b}$} \\
\hline Location (deg long.E, deg lat.N) & 139.52, 34.09 \\
\hline Radius (m) & $410 \pm 10$ \\
\hline Depth $(\mathrm{km})$ & $1.9 \pm 0.1$ \\
\hline Density change $\left(\mathrm{kg} / \mathrm{m}^{3}\right)$ & -1000 \\
\hline \multicolumn{2}{|l|}{ Tensile dislocation $I^{c}$} \\
\hline Location $^{d}$ (deg. long. E, deg. lat. N) & $139.37,34.13$ \\
\hline Depth to the top edge (m) & 1000 \\
\hline Length (m) & 20000 \\
\hline Height (m) & 10000 \\
\hline Strike & $\mathrm{N} 59^{\circ} \mathrm{W}$ \\
\hline Opening (m) & $\mathbf{1 . 6 0} \pm \mathbf{0 . 0 7}$ \\
\hline Ambient density $\left(\mathrm{kg} / \mathrm{m}^{3}\right)$ & 2670 \\
\hline Excess Density of intruded dike $e^{e}\left(\mathrm{~kg} / \mathrm{m}^{3}\right)$ & 183 \\
\hline \multicolumn{2}{|l|}{ Tensile dislocation $I I^{c}$} \\
\hline Location $^{d}$ (deg. long. E, deg. lat. N) & $139.25,34.23$ \\
\hline Depth to the top edge (m) & 1000 \\
\hline Length (m) & 13000 \\
\hline Height (m) & 10000 \\
\hline Strike & $\mathrm{N} 50^{\circ} \mathrm{W}$ \\
\hline Opening (m) & $4.80 \pm 0.02$ \\
\hline Ambient density $\left(\mathrm{kg} / \mathrm{m}^{3}\right)$ & 2670 \\
\hline Excess density of intruded dike $\left(\mathrm{kg} / \mathrm{m}^{3}\right)$ & 183 \\
\hline \multicolumn{2}{|l|}{ Strike slip ${ }^{c}$} \\
\hline Location $^{d}$ (deg. long. E, deg. lat. N) & $139.22,34.21$ \\
\hline Depth to the top edge $(\mathrm{m})$ & 500 \\
\hline Length (m) & 5000 \\
\hline Height (m) & 6000 \\
\hline Strike & $\mathrm{N} 85^{\circ} \mathrm{W}$ \\
\hline Slip (m) & $9.37 \pm \mathbf{0 . 1 3}$ \\
\hline
\end{tabular}

\footnotetext{
${ }^{a}$ Numbers in bold are optimized parameters, while others are fixed.

${ }^{b}$ For simplicity, we assumed a spherical body.

${ }^{c}$ Dip angle of all the dislocation sources is assumed to 90 degrees.

${ }^{d}$ The western edge of the dislocations is shown.

${ }^{e}$ See texts on the positive estimate.
}

\section{Gravity and Elevation Changes at Kozushima 3.1 Gravity changes}

Microgravimetry at an active volcano is a widely used technique that can reveal a redistribution of magma by sensing changes in the density distribution (e.g., Okubo and Watanabe, 1989; Rymer et al., 1995; Battaglia et al., 1999). In conventional microgravimetry, only relative gravimeters are employed to measure a spatial difference in gravity with respect to a fixed reference site, assuming the absolute gravity at the reference is temporarily constant. However, there is no warranty of temporarily constant gravity particularly on small active volcano islands. The current state-of-theart absolute gravimeter is transportable, and enables us to measure absolute gravity with an accuracy of less than $5 \mathrm{mi}-$ crogals $\left(=5 \times 10^{-8} \mathrm{~m} / \mathrm{s}^{2}\right)$ (Niebauer et al., 1995). We set up FG5\#109 at a reference site, and other benchmarks were tied using two or three LaCoste-Romberg G type gravimeters; we call this approach a hybrid microgravimetry (Tanaka et al., 2001; Furuya et al., 2003). The relative gravimetry was done in a round-trip manner mainly to estimate the drift rate of spring, and we can derive two-way differences which may be regarded as measurement error; they were normally $10 \sim 20$ microgals.

The microgravity survey at Kozushima prior to the volcano-seismic activities was made on March 2000. Resurveying was done on September 2000 at 11 sites of all the benchmarks. After the beginning of volcanic activity at Miyakejima on June 2000, we set up the absolute gravimeter at Miyakejima. Thus, the absolute gravity at Kozushima after the volcano-seismic activity was derived by tying the reference point at Miyakejima to that at Kozushima, using a helicopter. Detected gravity changes in Kozushima are shown in Fig. 2(a). The temporal absolute gravity change at the reference of Kozushima since March 2000 was determined to be $-29 \pm 15$ microgals. Spatial variation of the gravity changes within Kozushima are small, ranging from +10 to $-9.5 \mathrm{mi}-$ crogals with respect to the reference site. Namely, we see that all the sites underwent negative gravity changes. This observation result clearly illustrates the significance of measuring absolute gravity, so that we can detect gravity changes free from the ambiguity of absolute value. The inferred spatial trends are found to be geophysically plausible, as dis- 
cussed later on.

There occurred five large earthquakes which could generate appreciable co-seismic gravity changes, but we cannot infer the amount of co-seismic gravity changes included in Fig. 2(a), because the gravity measurement was not continuous in time. However, by employing the source model by Nishimura et al. (2001), we can estimate co-seismic gravity changes and find that they vary from -3 to -14 microgals in Kozushima. We may regard these changes as small since they are indistinguishable from measurement errors.

\subsection{Elevation changes}

The elevation changes in Fig. 2(b) were derived by leveling measurements on January 2000 and those on April 2001; the steep topography in the eastern part of Kozushima prevented the construction of a leveling network over the whole island. Despite the short length of about $6 \mathrm{~km}$ in total, the northern part of the islands turned out to have subsided by as much as $9 \mathrm{~cm}$ with respect to the southern part. Like the relative gravimeters, the leveling technique alone does not allow us to detect absolute height changes. The GPS site of the Japan Hydrographic Department at almost the same location as the absolute gravity site (Fig. 2) showed an uplift by as much as $25 \mathrm{~cm}$ after the intense seismic swarms in 2000 . Meanwhile, the co-seismic uplift was evaluated as $8 \mathrm{~cm}$ in light of the continuous GPS measurement at Kozushima, and thus we added an uplift of $17 \mathrm{~cm}$ to the reference at Kozushima. Hence, we see that Kozushima underwent an overall uplift together with a downward tilt to the northern part of the island.

\section{Gravity and Elevation Changes at Miyakejima 4.1 Gravity changes}

Effective gravity changes since June 1998 until the middle August 2000 are shown in Fig. 3(a). By "effective" we mean that the gravity changes due to the topography change by the caldera collapse are self-evident and are already corrected for; a detailed procedure is discussed in the appendix of Furuya et al. (2003). Co-seismic gravity changes due to large earthquakes are computed based upon the model by Nishimura et al. (2001), and turn out to range from -7 to -3 microgals. Thus we may regard them as negligible. For the correction of the topography change, we assumed a density value of $2300 \mathrm{~kg} / \mathrm{m}^{3}$. Despite the ground subsidence and contraction, we found that gravity values had decreased from the beginning of the unrest to August 2000 particularly over the northern part of the islands. When we prescribed a smaller density, the area of gravity decrease gets smaller. But, even when we used $1900 \mathrm{~kg} / \mathrm{m}^{3}$, we can recognize a temporal gravity decrease at the northern area. Meanwhile, both a localized increase at as much as $99 \mu$ gals in the southwestern site and the regional increases over the southern part of the island were already seen in the beginning of July 2000; they are interpreted to be caused by dike intrusion in the south-western part of the island and deflation of the magma chamber beneath the volcano (Furuya et al., 2003).

\subsection{Elevation changes}

Shown in Figure 3(c) are the elevation changes derived from the leveling measurement on June 1999 and January 2002. In order to estimate the absolute elevation change at the benchmark of the tide gauge station, height changes at the GPS sites were first derived; Tsukuba station was assumed to be fixed in the estimation of the height change. Next, they were combined with the elevation difference of the tide gauge station relative to the GPS sites at the two different epochs. Though the ground displacement associated with the 2000 unrest did not completely stop even on January 2002, both Miyakejima and other islands underwent more than $90 \%$ of the total ground displacements from the beginning of the 2000 unrest until September 2000. As well, ground displacement trends never reversed their sign after the beginning of the 2000 Miyakejima unrest. The vertical deformation before the 2000 unrest is also probably negligible. Therefore, the observed elevation changes could be considered as have been caused by the middle of August 2000. It should also be noted that the precision of the levelling measurement is much superior to that of GPS. The co-seismic changes in elevation can be estimated to be less than $4 \mathrm{~cm}$. Though these are well-within the detection limit of the leveling technique, the derived whole elevation changes greatly exceed these estimates of co-seismic changes in elevation. Thus, the optimum parameters derived later will not change substantially, even if we regard these effects as negligible.

Ground subsidence in the southern part of the island turns out to be much greater than that in the northern part. Maximum detected subsidence reached as much as $105 \mathrm{~cm}$ at the middle flank in the south-eastern area. In contrast, a minimum subsidence of as much as $12.5 \mathrm{~cm}$ can be seen at the northernmost site; the absolute gravity site is closest to the minimum subsidence site. Smaller subsidence in the northern part of the island probably made it easier to show a gravity decrease in this area (Fig. 3(a)). We also see a regional subsidence as much as $95 \mathrm{~cm}$ in the south-western site, where we detected a similar regional gravity increase (Fig. 3(a)).

\section{Modeling the Geodetic Observation \\ 5.1 Source model}

In order to account for the changes in gravity and elevation at Kozushima and Miyakejima (Figs. 2 and 3) as well as for the horizontal displacements detected by GPS at other nearby Izu-islands (Fig. 4), we construct a source model as shown in Fig. 5. Though our model is quite similar to the model of Nishimura et al. (2001), one important difference is that we need to include another source element in order to explain the effective gravity decrease at Miyakejima.

In order to represent the dike intrusion at the southwest of Miyakejima, we employ a rectangular tensile dislocation source, based on an analytical expression developed by Okada (1985) for ground displacements and one by Okubo (1992) for gravity changes, respectively. A preliminary analysis shows that single rectangular tensile dislocation fails to explain the overall changes, most probably because the width of the tensile opening varies laterally as discussed below. Though the actual shape of the intruded dike would be more complicated, we included two tensile dislocations such as those described by Nishimura et al. (2001), one in the south-western region at Miyakejima and the other offshore south-east of Kozushima (Fig. 5), and estimate the opening of tensile dislocation (Table 1). Since all the source parameters cannot be optimized simultaneously, we fixed many of them, referring mainly to the hypocenter distribu- 


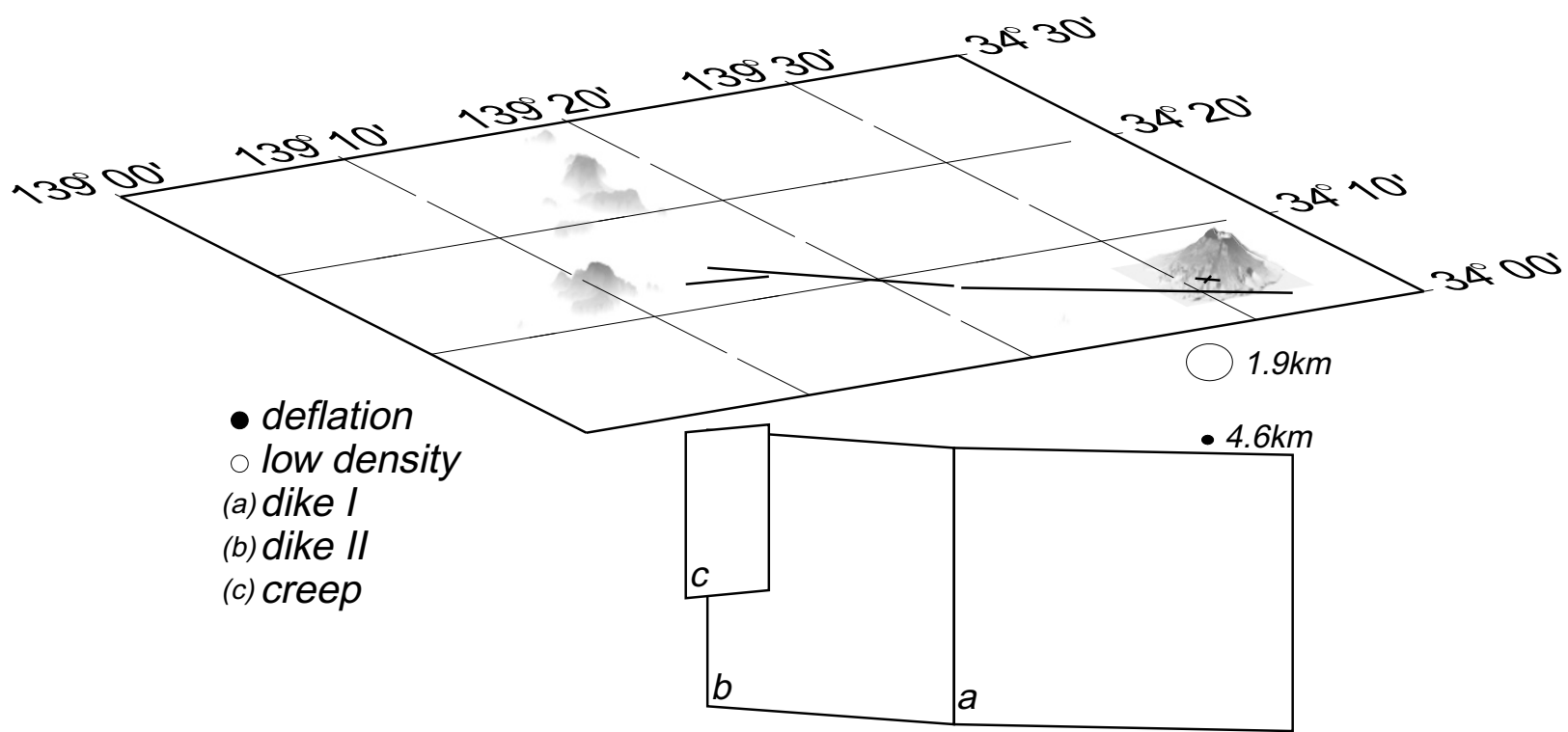

Fig. 5. 3-D view of source model for the ground displacements and gravity changes which are caused by the 2000 Miyakejima volcanic unrest and ground displacements nearby Izu-islands, Japan. Five elements are used, i.e., (i) Mogi-type deflation source, (ii) Lightened body, (iii) Tensile dislocation I, (iv) Tensile dislocation II and (v) Strike slip fault. The depth of the top edge of tensile dislocation I is $1000 \mathrm{~m}$, and its height is $10 \mathrm{~km}$; see Table $1 \mathrm{for}$ details. The elevation map of the Izu-islands is based on GSI's digital elevation models of 50-meter resolution except at Miyakejima, whose resolution is 10 -meter.

tions (Sakai et al., 2001); though the estimates of hypocenter depths depend on the prescribed velocity structure, they were distributed from 1-2 km below sea level to a depth of less than $15 \mathrm{~km}$. Moreover, as suggested by Yamaoka (2000), we included a right lateral aseismic fault and optimized the amount of strike slip below (Fig. 5). This source element is required because the two tensile dislocations alone cannot explain the ground displacements in the northern Izu-islands, particularly the displacement at Shikinejima. As a geophysical reasoning for the aseismic fault, Yamaoka (2000) speculated that the temperature below the area between Shikinejima and Kozushima would be high, because the number of aftershocks of the 1 July 2000 earthquake (M6.4) were fewer, and because this area is close to the location of the fore-mentioned inflation source (Kimata et al., 2000). Also, in light of the $\mathrm{Q}^{-1}$ tomography based upon strong motion data (T. Furumura, personal communication), we can recognize a highly attenuated region, which may support the existence of aseismic creep motion. Since this is an aseismic fault, the length and height of the fault plane cannot be determined based on hypocenter distribution. Though Nishimura et al. (2001) optimized almost all source parameters for the aseismic fault, we fixed many other parameters, refering to the location and size of the highly attenuated area, and optimized only the slip amount.

The gravity increase and larger subsidence in the southeastern region of Miyakejima can be explained by a deflation source (Mogi, 1958), and we estimate the location and volume changes. Despite the ground contraction and subsidence at Miyakejima, the effective gravity values at Miyakejima continued to decrease until the middle of August 2000 (Fig. 3); see also Furuya et al. (2003). We think that lateral magma flow continued until middle August 2000. The temporal gravity decrease suggests a reduction of density beneath the Miyakejima volcano, which probably represents a mass deficit due to the lateral flow. We think that the lateral flow led to an internal collapse of the space beneath the volcano, and that the subsequent fractured region underwent an exchange of original matter with water inflow from the ambient aquifer; it may accordingly promote an intense magma-water interaction and subsequent explosive eruptions (Furuya et al., 2003). For simplicity, we employ a spherical cavity for the region of density reduction, whose density value is assumed to be smaller by as much as $1000 \mathrm{~kg} / \mathrm{m}^{3}$ than that of the original rock (Furuya et al., 2003), and estimate its location and volume below (Fig. 5).

\subsection{Results and Discussion}

With some of the source parameters fixed as in Table 1, we carried out a simplex search in order to determine the optimum parameters that could minimize the following quantity $L:$

$$
\begin{aligned}
L= & \sum_{i=1}^{15}\left(\frac{g_{i}^{o b s}-g_{i}^{c a l}}{\sigma_{g m}}\right)^{2}+\sum_{i=1}^{29}\left(\frac{e_{i}^{o b s}-e_{i}^{c a l}}{\sigma_{e m}}\right)^{2} \\
& +\sum_{i=1}^{11}\left(\frac{g_{i}^{o b s}-g_{i}^{c a l}}{\sigma_{g k}}\right)^{2}+\sum_{i=1}^{28}\left(\frac{e_{i}^{o b s}-e_{i}^{c a l}}{\sigma_{e k}}\right)^{2} \\
& +\sum_{i=1}^{15}\left(\frac{\overrightarrow{\mathrm{d}_{i}^{o b s}}-\overrightarrow{\mathrm{d}_{i}^{c a l}}}{\sigma_{g p s}}\right)^{2}
\end{aligned}
$$

where $g, e$, and d represent gravity change, elevation change, and ground horizontal displacement derived by GPS, respectively, and $\sigma_{g m}, \sigma_{e m}, \sigma_{g k}, \sigma_{e k}$, and $\sigma_{g p s}$ are $50 \mu \mathrm{gal}, 30 \mathrm{~mm}$, $40 \mu \mathrm{gal}, 30 \mathrm{~mm}$, and $30 \mathrm{~mm}$, respectively. The subscripts, $g, e, m$, and $k$ represent gravity, elevation, Miyakejima, and Kozushima, respectively. The larger $\sigma_{g m}$ considers our inaccurate estimate of the correction of collapse effect upon gravity changes. Because the minimization of $L$ is highly dependent upon the prescribed pair of initial values, we tried a number of physically plausible sets of initial values, so that 
Table 2. Mass flow around Miyakejima and Kozushima.

\begin{tabular}{llccc}
\hline \multicolumn{1}{c}{ Mechanism } & \multicolumn{1}{c}{ Where } & $\begin{array}{c}\text { Volume } \\
\left(\times 10^{9} \mathrm{~m}^{3}\right)\end{array}$ & $\begin{array}{c}\text { Density } \\
\left(\mathrm{kg} / \mathrm{m}^{3}\right)\end{array}$ & $\begin{array}{c}\text { Mass change } \\
\left(\times 10^{9} \text { tons }\right)\end{array}$ \\
\hline Caldera collapse & At Miyakejima & -0.6 & 2300 & -1.38 \\
Deflation & Beneath Miyakejima & -0.13 & 2670 & -0.35 \\
Internal collapse & Beneath Miyakejima & 0.29 & -1000 & -0.29 \\
Tensile dislocation I & Offshore Miyakejima & +0.32 & 2853 & +0.91 \\
Tensile dislocation II & Offshore Kozushima & +0.62 & 2853 & +1.78 \\
\hline
\end{tabular}

optimum values are as robust as possible. The optimum parameters and their uncertainties are shown in Table 1, and the computed changes of gravity, elevation, and horizontal positions of GPS sites are shown in Figs. 2, 3, and 4. The inferred deflation source at Miyakejima was estimated to be close to the caldera at a depth of $4.6 \mathrm{~km}$. The deflation volume was $0.13 \mathrm{~km}^{3}$.

The horizontal location of the "lightened" space is not distant from the deflation source, but its depth is estimated to be $1.9 \mathrm{~km}$. The estimated volumes of "lightened" space amount to $0.29 \mathrm{~km}^{3}$, whose volume is about half of the final volume of the caldera on the ground surface. With the density values as prescribed before, the mass that disappeared from the ground surface and beneath the Miyakejima until late August 2000 can be estimated as $2.02 \times 10^{9}$ tons (Table 2 ).

Meanwhile, the two tensile dislocations near Miyakejima and Kozushima were estimated to have opened by 1.6 and $4.8 \mathrm{~m}$, respectively (Table 1). Despite the appreciable difference in the prescribed length and width of the faults from those prescribed by Nishimura et al. (2001), the optimized sizes of the two tensile opening is largely consistent in respect that the opening size near Kozushima is significantly larger than the other near Miyakejima. Theoretically, while both gravity increase and ground subsidence are expected at immediately above and near the edge of a vertically standing tensile opening, we can predict ground uplift as well as a gravity decrease at some distance from the tensile opening. The observed overall uplift, gravity decrease and their spatial trends at Kozushima can be well-explained by the estimated large tensile opening at that location.

Using gravity change data, we can place an interesting constraint upon the density inside the tensile dislocation. Though the optimum value highly depends upon the prescribed initial value, we evaluated it to be greater by as much as $180 \mathrm{~kg} / \mathrm{m}^{3}$ than the ambient material. In the minimization process of the $L$ above, we also tried negative initial values for the density difference. However, the density difference was optimized to be positive regardless of the sign of the initial value, and, to say the least, the filled matter was denser than the ambient material. This inferred larger density suggests its inability to ascend and may account for why no sea floor eruption occurred just above the seismic swarm area. We do not claim, however, that the dense magma did "actively" ascend from the dormant reservoir. As discussed later on, our speculation is that the dense magma was sucked up and "passively" ascended.

The mass change due to the tensile opening can be evaluated as $1.78 \times 10^{9}$ tons for dike II (Fig. 5) and $0.91 \times 10^{9}$ tons for dike I (Fig. 5), respectively. Comparing the lost mass at Miyakejima with the intruded mass as dike offshore of the Miyakejima and the Kozushima (Table 2), the mass of the latter is larger than the former by as much as $33 \pm 10 \%$. Hence, though the mass from Miyakejima can indeed be accommodated as a laterally migrated flow, it is significantly smaller than the whole mass of the opening tensile sources. Thus we may conclude that another magma reservoir existed close to Kozushima, and that another mass than that from Miyakejima did actually intrude as a dike during the period of intense seismic swarm in 2000. However, the hypocenter migration from Miyakejima in the very beginning presumably represents a lateral magma flow from Miyakejima. Though the quantitative mechanism remains to be clarified, we consider from a phenomenological point of view that lateral magma flow from Miyakejima awakened a dormant magma reservoir near Kozushima (Fig. 6(b)). Under the background stress field as mentioned before (Nakamura et al., 1984), the dense magma might have been sucked up and "passively" ascended. Consequently, two magma sources caused the intense seismic swarms and crustal deformation (Fig. 6(c)). After the largest eruption on 18 August 2000, the lateral flow from Miyakejima terminated, leading the ground movements at the northern Izu-islands dramatically to slow in September 2000 (Fig. 6(d)). As a caveat, however, it should be noted that the mass budget computation above considers only the source elements which could generate appreciable changes in the geodetic data on the land surface. We can think that another extra magma source at much deeper depth than the shallower deflation source was supplied contemporaneously at Miyakejima (Figs. 6(b) and 6(c)). The ground displacements from such a deeper source would be small, and would be masked by the more significant displacements due to the shallower source. The significant mass difference noted above might be accommodated to this unmonitored deeper source beneath Miyakejima, and another magma reservoir near Kozushima might be unnecessary.

The right-lateral strike slip of the shear fault is estimated to be $9.7 \mathrm{~m}$. Though the seismic moment of this fault model is almost equal to that described by Nishimura et al. (2001), there are appreciable differences in the size and location. This model may be regarded as an alternative to Nishimura et al's model, but the present geodetic data regarding only the land surface does not have a strong enough resolving power to constrain the aseismic fault parameters. Meanwhile, Yamaoka et al. (2002) reanalyzed GSI's GPS displacements over a wider region and showed that, without employing 
(a) Before 26 June 2000

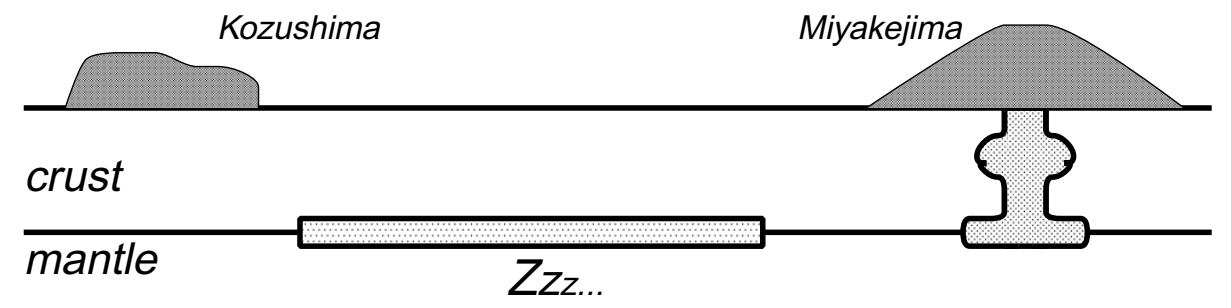

(b) In the very beginning,...

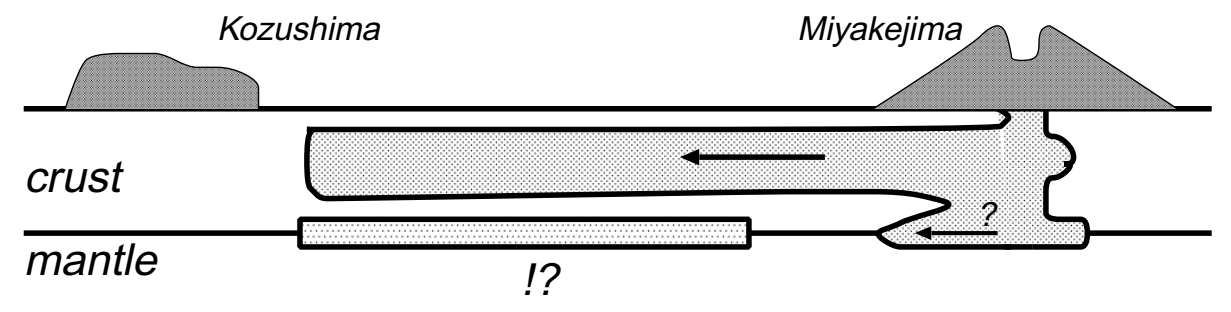

(c) During the most intensive swarms

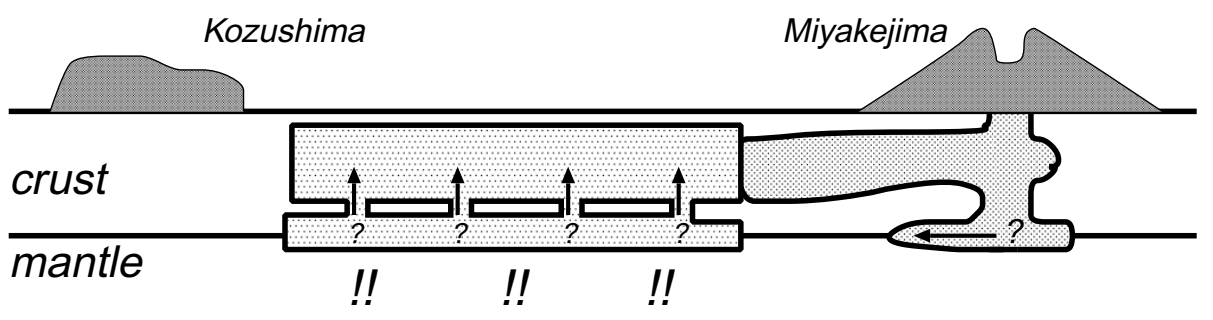

(d) After the largest eruption on 18 August 2000

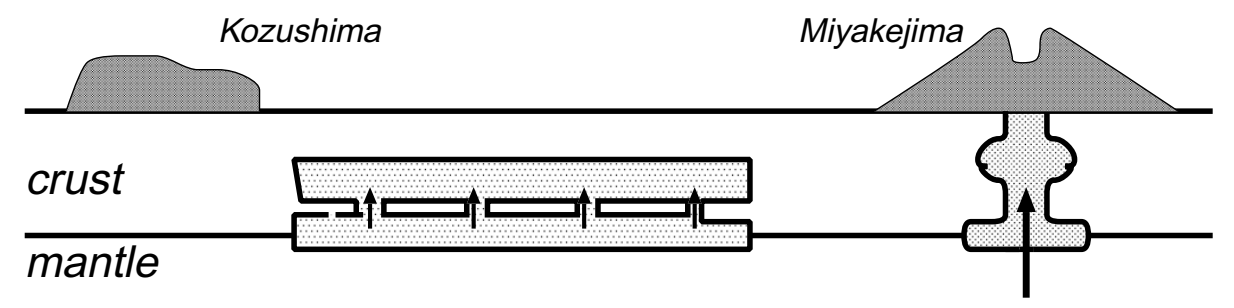

Fig. 6. Speculations on what occurred during 2000 Miyake-Kozu volcano seismic activity. (a) Before 26 June 2000 , the magma reservoir beneath the offshore of Miyakejima has been dormant. (b) In the very beginning of the 2000 activity, magma migrated from Miyakejima toward Kozushima, and the dormant reservoir was awakened. (c) The magma reservoir near Kozushima was activated, and caused the most intensive seismic swarms and crustal deformation. (d) After the largest eruption on 18 August 2000, the lateral magma flow terminated, and the activated magma reservoir became inactive.

right-lateral creep fault, a deflation source together with a tensile dike could also explain the overall ground displacement. Their new model also requires another magma reservoir nearby Kozushima.

\section{Summary}

We detected significant changes in gravity and elevation at Miyakejima and Kozushima, which are associated with the 2000 volcano-seismic activity. We developed a source model accounting for the changes in gravity and elevation changes as well as ground displacements by GPS. As a result, sin- gle longer rectangular dislocation fails to explain the ground displacements in the northern Izu-islands, and we need to consider lateral variations in the tensile opening. The tensile opening nearby Kozushima was larger than that nearby Miyakejima. In view of the mass budget, another magma reservoir is suggested nearby Kozushima besides that beneath Miyakejima. A dormant magma reservoir might have been activated by the lateral magma flow from Miyakejima, causing the long-lasting swarms.

Acknowledgments. We thank the staffs of the Miyakejima 
Weather Station, Japan Meteorological Agency, Martime Safety Agency, Japan Defense Agency, Miyake Village, Kozu Village, Naka-nihon airlines and the Tokyo Metropolitan Government for their support of our gravimetry and leveling measurements. We also acknowledge the Geographical Survey Institute of Japan for GPS data and digital elevation maps that have been made publicly available for research purposes. Comments by Dr. T. Nishimura and an anonymous reviewer are greatly appreciated. Some of the figures in this paper were prepared using GMT (Wessel and Smith, 1998).

\section{References}

Battaglia, M., G. Roberts, and P. Segall, Magma intrusion beneath long valley caldera confirmed by temporal changes in gravity, Science, $\mathbf{2 8 5}$ 2119-2122, 1999.

Dvorak, J. J. and D. Dzurisin, Volcano geodesy: The search for magma reservoirs and the formation of eruptive vents, Rev. Geophys., 35(3), 343 384, 1997.

Furuya, M., S. Okubo, W. Sun, Y. Tanaka, J. Oikawa, H. Watanabe, and T. Maekawa, Spatio-temporal gravity changes at Miyakejima volcano, Japan: Caldera collapse, explosive eruptions and magma movement, $J$ Geophys. Res., 108(B4), 2219, doi:10.1029/2002JB001989, 2003.

Hasegawa, H., M. Murakami, H. Masaharu, K. Matsuo, and M. Koarai, Caldera subsidence measurement at Miyakejima summit, J. Geogr. Surv. Inst., 95, 121-128, 2001 (in Japanese).

Japan Meteorological Agency, National Catalogue of the Active Volcanoes in Japan-Second Edition-, Printing Bureau, Ministry of Finance, Japan, 500 pp, 1996 (in Japanese).

Japan Meteorological Agency, Recent seismic activity in the Miyakejima and Niijima-Kozushima region, Japan - the largest earthquake swarm ever recorded-, Earth Planets Space, 52, i-viii, 2000.

Kaidzu, M., T. Nishimura, M. Murakami, S. Ozawa, T. Sagiya, H. Yarai, and T. Imakiire, Crustal deformation associated with crustal activities in the northern Izu-islands area during the summer, 2000, Earth Planets Space, 52, ix-xviii, 2000.

Kimata, F., M. Satomura, Y. Sasaki, I. Murata, and K. Fuse, GPS measurements in the Tokai region and Izu Hachijo islands, Proceedings of the CRCM'93, 225-227, 1994

Kimata, F., S. Kariya, M. Fujita, K. Matsumoto, T. Tabei, J. Segawa, and A. Yamada, Estimated pressure source on Kozu Island volcano, South Central Japan, from GPS measurements (July 1996-August 1999), Earth Planets Space, 52, 975-978, 2000.

Miyazaki, T., Features of Historical Eruptions at Miyake-jima Volcano, Bull. Volcanol. Soc. Japan, 11, S1-S15, 1984 (in Japanese with English abstract).

Mogi, K., Relations between the eruptions of various volcanoes and deformations of the ground surfaces around them, Bull. Earthq. Res. Inst., 36,
99-134, 1958.

Nakada, S., M. Nagai, A. Yasuda, T. Shimano, N. Geshi, M. Ohno, T. Akimasa, T. Kaneko, and T. Fujii, Chronology of the Miyakejima 2000 Eruption: Characteristics of summit collapsed crater and eruption products, $J$. Geogr., 110(2), 168-180, 2001 (in Japanese with English abstract).

Nakamura, K., K. Shimazaki, and N. Yonekura, Subduction, bending and eduction. Present and Quaternary tectonics of northern border of the Philippine Sea Plate, Bull. Soc. geol. France., 26(2), 221-243, 1984.

Niebauer, T. M., G. Sasagawa, J. E. Faller, R. Hilt, and F. J. Klopping, A new generation of absolute gravimeters, Metrologia, 32, 159-180, 1995.

Nishimura, T., S. Ozawa, M. Murakami, T. Sagiya, T. Tada, M. Kaidzu, and M. Ukawa, Crustal deformation caused by magma migration in the northern Izu Islands, Japan, Geophys. Res. Lett., 28, 3745-3748, 2001.

Okada, Y., Surface deformation due to shear and tensile faults in a halfspace, Bull. Seismol. Soc. Am., 75, 1135-1154, 1985.

Okubo, S., Potential and gravity changes due to shear and tensile faults in a half-space, J. Geophys. Res., 97, 7137-7144, 1992.

Okubo, S. and H. Watanabe, Gravity change caused by a fissure eruption, Geophys. Res. Lett., 16, 445-448, 1989.

Rymer, H., J. Cassidy, C. A. Locke, and J. B. Murray, Magma movements in Etna volcano associated with the major 1991-1993 lava eruption: evidence from gravity and deformation, Bull. Volcanol., 57, 451-461, 1995.

Sakai, S., T. Yamada, S. Ide, M. Mochizuki, H. Shiobara, T. Urabe, N. Hirata, M. Shinohara, T. Kanazawa, A. Nishizawa, G. Fujie, and H Mikada, Magma migration from the point of view of seismic activity in the volcanism of Miyake-jima Island in 2000, J. Geogr, 110(2), 145-155, 2001 (in Japanese with English abstract).

Tanaka, Y., S. Okubo, M. Machida, I. Kimura, and T. Kosuge, First detection of absolute gravity change caused by earthquake, Geophys. Res. Lett., 28 , 2979-2981, 2001

Tsukui, M. and M. Suzuki, Eruptive history of Miyakejima Volcano during the last 7000 years, Bull. Volcanol. Soc. Japan, 43, 149-166, 1998 (in Japanese with English abstract).

Wessel, P. and W. H. F. Smith, New, improved version of Generic Mapping Tools released, Eos Trans. AGU, 79(47), 579, 1998

Yamaoka, K., What is happening beneath the ground of Miyakejima and Kozushima? - search for the origin the seismo-volcanic activity-, $\mathrm{Ka}$ gaku, 70(11), 926-935, 2000 (in Japanese).

Yamaoka, K., M. Kudo, M. Kawamura, F. Kimata, and N. Fujii, Longlasting dike intrusion in the 2000 eruption of Miyake-Jima VolcanoWhere did the magma come from?-, J. Volcanol. Geotherm. Res., 2002 (submitted).

M.Furuya (e-mail: furuya@eri.u-tokyo.ac.jp) S. Okubo, F. Kimata, R. Miyajima, I. Meilano, W. Sun, Y. Tanaka, and T. Miyazaki 